\title{
Significados de um projeto social esportivo: um estudo a partir das perspectivas de profissionais, pais, crianças e adolescentes
}

\author{
Suélen Barbosa Eiras de Castro* \\ Doralice Lange Souza**
}

\begin{abstract}
Resumo: Este trabalho teve como objetivo explorar os principais significados atribuídos ao projeto Esporte em Ação - Núcleo Vila Torres, Curitiba/PR, a partir da percepção de alunos, pais de alunos e profissionais envolvidos com o projeto. A pesquisa foi de natureza qualitativa e de cunho exploratório, e os dados coletados através de entrevistas semi-estruturadas e abertas com profissionais, pais e alunos. A análise foi feita com base em procedimentos da teoria fundamentada. Concluiu-se que o projeto é percebido como um espaço que protege os participantes de "males das ruas", como um espaço de aprendizagem e como um espaço para se jogar, brincar, se divertir e estar com amigos.
\end{abstract}

Palavras chave: Projeto social. Crianças. Adolescentes.

\section{INTRODUÇÃO}

O número dos projetos sociais esportivos promovidos por órgãos públicos, instituições privadas e organizações não-governamentais (ONGs) aumentou significativamente em todo o país ganhando visibilidade na mídia e na sociedade (ZALUAR, 1994; MELO, 2004; 2005; 2007a; 2007b; BARBIRATO, 2005; GUEDES et al., 2006; THOMASSIM, 2006; 2007; 2010). A maior parte destes projetos está voltada à crianças e jovens pobres, classificados algumas vezes como em "situação de risco social" ou em "situação de vulnerabilidade

\footnotetext{
"Mestre em Educação Física pela Universidade Federal do Paraná - e-mail: sueleneiras@hotmail.com

"Professora do Departamento de Educação Física da Universidade Federal do Paraná. Centro de Pesquisas em Esporte, Lazer e Sociedade da UFPR - email: dora@ufpr.br
} 
social" e objetivam ocupar o tempo livre dos mesmos (GONÇALVES, 2003; GUEDES et al., 2006; BRETÂS, 2007; MELO, 2007a; 2007b; THOMASSIM, 2007).

Consecutivamente ao crescimento do número de projetos sociais esportivos, aumenta também a crença nas vantagens do esporte (THOMASSIM; STIGGER, 2009) enquanto um meio de educação (GONÇALVES, 2003; BARBIRATO, 2005; GUEDES et al., 2006; VARGAS, 2007; MELLO; FERREIRA NETO; VOTRE, 2009; THOMASSIM; STIGGER, 2009; THOMASSIM, 2010). Existe uma expectativa de que, através de vivências esportivas, crianças e adolescentes adquiram conteúdos simbólicos e comportamentos "úteis" para suas vidas, bem como vislumbrem novas perspectivas de futuro (THOMASSIM, 2010).

Considerando o aumento do número de projetos sociais esportivos e a suposta relevância dos mesmos para seus participantes e famílias, desenvolvemos uma pesquisa sobre um projeto em específico, o projeto Esporte em Ação - Núcleo Vila Torres (EAVT), em Curitiba/PR. Visamos com este estudo, contribuir para com o desenvolvimento da literatura ainda escassa sobre projetos sociais esportivos, bem como para com o desenvolvimento do projeto estudado e de outros similares. O estudo teve como objetivo explorar os principais significados ${ }^{1}$ do projeto Esporte em Ação - Núcleo Vila Torres (EA-VT) em Curitiba/PR, a partir da percepção de alunos, pais de alunos e profissionais envolvidos com o projeto.

\section{Metodologia}

A pesquisa foi de natureza qualitativa e de cunho exploratório ${ }^{2}$ e teve como objeto de estudo o projeto Esporte em Ação - Núcleo Vila Torres (EA-VT). Este projeto é desenvolvido na Praça Plínio

\footnotetext{
'A palavra "significado" no contexto deste trabalho denota "sentido".

"Este estudo é parte de um projeto de pesquisa maior onde exploramos diferentes barreiras e facilitadores para a implementação e participação em programas de contraturno escolar. Desta forma, ele envolveu a participação de alunos bolsistas e voluntários ligados à Rede CEDES e aos Programas Licenciar e de Iniciação Científica da UFPR.
} 
Tourinho, Curitiba/PR e é coordenado pelo Instituto Compartilhar (IC) em parceira com a Prefeitura Municipal de Curitiba (PMC), através da Fundação de Ação Social (FAS) e da Secretaria Municipal de Esporte e Lazer (SMEL) ${ }^{3}$. Na época em que coletamos os dados, de maio a dezembro de 2009, o EA-VT atendia aproximadamente a 90 crianças e adolescentes com idades entre 08 e 15 anos residentes na Vila Torres - um bairro carente e que enfrenta sérios problemas sociais - inseridas no Programa de Erradicação do Trabalho Infantil $(\mathrm{PETI})^{4}$. O projeto oferece a prática de modalidades esportivas e atividades complementares como apoio escolar, eventos, oficinas, palestras e lanche (INSTITUTO COMPARTILHAR, 2009).

Coletamos os dados através de entrevistas semi-estruturadas, abertas e aprofundadas, uma vez que queríamos garantir que iríamos fazer determinadas perguntas para todos os participantes, mas ao mesmo tempo desejávamos também um grau de liberdade para explorar os temas que iam emergindo durante as entrevistas e interações com os participantes (PATTON, 1990). Entrevistamos 52 alunos, 09 pais de participantes e 17 profissionais. As entrevistas com profissionais envolveram funcionários do Instituto Compartilhar (o gerente executivo, 01 psicóloga e 04 professores) e da Prefeitura Municipal de Curitiba (08 educadores sociais, 02 assistentes sociais e 01 auxiliar de serviços gerais). As entrevistas com pais de participantes envolveram 09 mulheres, sendo estas mães, madrastas e avós de crianças e adolescentes alunos do projeto. A idade dos alunos entrevistados variava entre 08 a 15 anos e o tempo de participação dos mesmos no projeto variava entre 02 semanas e 07 anos. Para desenvolver e contextualizar as questões das entrevistas e temas que emergiam das nossas interações com os alunos, realizamos algumas observações assistemáticas e lemos documentos

\footnotetext{
${ }^{3} \mathrm{O}$ IC é responsável por coordenar e administrar as atividades esportivas nas modalidades de voleibol, futebol de areia e capoeira; a FAS é responsável por coordenar as ações sócio educativas e acompanhar as crianças, adolescentes e suas famílias; a SMEL é responsável pelo espaço da praça e pela disponibilização de professores e estagiários para as modalidades de basquetebol e futsal (INSTITUTO COMPARTILHAR, 2009).

${ }^{4} \mathrm{O}$ projeto Esporte em Ação - Núcleo Vila Torres encerrou suas atividades em dezembro de 2010.
} 
disponíveis relativos ao projeto tais como panfletos informativos, páginas informativas da internet e relatórios de trabalho. As observações e leitura de documentos, no entanto, dado o escopo deste estudo, não foram objetos de nossa análise.

O processo de análise dos dados se deu com base em procedimentos da teoria fundamentada (GLASER; STRAUSS, 1967; STRAUSS; CORBIN, 1990). Primeiramente analisamos cada uma das entrevistas, identificando os temas mais importantes que emergiram das falas de cada um dos sujeitos, agrupando-os em categorias. Em um segundo momento, cruzamos os dados comparando as análises e temas que surgiram a partir das falas de todos os sujeitos, buscando as similaridades e diferenças existentes entre os mesmos. Através deste procedimento, buscamos criar novas categorias - categorias mais abrangentes - para agrupar temas compatíveis. Estas categorias maiores se refletem nos resultados que apresentaremos a seguir.

\section{Resultados e Discussão}

Os principais achados da pesquisa podem ser classificados em três temas principais: $O$ projeto como um espaço seguro, como um espaço de aprendizagem e como um espaço para se brincar, jogar e se divertir. A fim de garantir o anonimato dos entrevistados, na apresentação destes temas, utilizaremos apenas nomes fictícios.

\subsection{O PROJETO COMO UM ESPAÇO SEGURO}

Os profissionais, mães e alunos entrevistados percebem o tempo ocioso como negativo. No EA-VT, como em outros projetos, existe uma preocupação para que crianças não fiquem "entregues a si mesmas" nas ruas (THIN, 2006, p. 216). Conforme aponta Zaluar 1994 (p. 40), "'tirar a criança da rua' tornou-se um lema e problema nacionais". 
De acordo com todos os profissionais, mães e vários alunos, o projeto protege de uma possível socialização ${ }^{5}$ "negativa" nas ruas, onde crianças e adolescentes podem se envolver com "más influências" e aprender "coisas que não prestam"6. Vejamos, por exemplo, as seguintes passagens de entrevistas:

Se ficar na rua só aprende o que não presta. [...] Então eu prefiro que ela esteja aqui, que aí ela já tá aprendendo, ela tá estudando, tem alguma coisa a fazer, né? (Zuleica, mãe)

Acho [o projeto importante], porque daí não fica na rua. [...] Não fica se metendo em coisa errada, sabe? [...] [Lá na Vila] eles mexem com drogas, armas, daí eles acabam se envolvendo, né? (Paola, 12 anos, aluno)

Enquanto eles tão aqui eles não tão lá na deixa do traficante, eles não tão passando fome, não tão aprontando na rua $[\ldots]$ estão protegidos. (Laura, profissional FAS)

Pais (ZALUAR, 1994; MENDES et al., 2006; VARGAS, 2007) e profissionais em outros projetos sociais também percebem os mesmos como espaços que ocupam o tempo ocioso e protegem contra males das ruas tais como más companhias, drogas e criminalidade (ZALUAR, 1994; GONÇALVES, 2003).

Para todos os profissionais e pais, bem como para vários alunos, o EA-VT também protege da violência das ruas.

A gente não perde tempo de ficar na rua, a gente pode ser atropelado, levar bala perdida e no projeto tem mais segurança. (Sheila, 10 anos, aluno)

Ás vezes na rua não pode ficar livre e aqui tem como ficar mais protegido. Ali no bairro eles podem

\footnotetext{
${ }^{5} \mathrm{O}$ conceito de socialização é aqui entendido no sentido ampliado do conceito de aprendizagem. Ou seja, "a transmissão e assimilação de padrões de comportamento, normas, valores e crenças, bem como o desenvolvimento de atitudes e sentimentos coletivos pela comunicação simbólica" (VILA NOVA, 1981, p. 31).

${ }^{6}$ Expressões utilizadas por entrevistados.
}

Movimento, Porto Alegre, v. 17, n. 04, p. 145-163, out/dez de 2011. 
fazer esportes, mas tá correndo risco. (Karina, profissional FAS)

Perto da minha casa tem briga de gangue e às vezes dá muito tiroteio, e eles ficando aqui, eu fico mais tranqüila. (Fernanda, mãe)

Embora a ocupação do tempo ocioso no projeto seja entendido como uma forma de proteção de determinados "males", alguns profissionais, mães e alunos reconhecem que a participação no projeto por si só não garante o não envolvimento com problemas.

Então a gente teve até casos de alunos daqui que se envolveram. Até teve um, [...] [que] faleceu. [...] Outros casos também que a gente sabe de meninas que se envolveram com prostituição, que estão usufruindo de drogas, tão vendendo, né? (Estela, profissional IC)

Eu já perdi bastante amigo aqui que vinha pra cá, ficava se envolvendo em droga e acabou [pausa] indo pra fita ${ }^{7}$ [morrendo]. [...] Eles acabam indo, acaba viciando nas coisas que não é devido, acaba que se perdendo. [...] Eles vinha [pro projeto], mas daí pararam de vir (Yasmin, 13 anos, participante)

Todos os profissionais e pais, bem como vários alunos entrevistados também alegaram que, embora o projeto seja um local seguro, o trajeto até o mesmo é preocupante, devido a problemas relacionados com o tráfico de drogas e rixas entre traficantes.

É o caminho, o trajeto de vir. [...] É uma dificuldade. Essa é a dificuldade. É a própria dificuldade. [...] Aqui por mais que tenha qualquer coisa assim chamativa, esporte, uma brincadeira, qualquer coisa, mesmo tendo assim problema lá não vai resolver. Porque o problema tá ali. Aqui pode fazer o que quiser mesmo que tenha [...] uma coisa boa aqui ninguém vai escolher, né? "Ah, eu vou lá me divertir, vou lá ganhar isso ou vou fazer isso, mas eu tô

\footnotetext{
7"Ir para a fita", segundo as crianças e adolescentes entrevistados, significa "morrer".
} 
colocando minha vida em risco. Primeiro eu vou defender a minha vida, né?" (Karina, profissional FAS)

Segundo vários depoimentos durante as entrevistas, tiroteios não são incomuns na Vila Torres. Isto gera medo tanto nas mães quanto nos alunos, impedindo os últimos de irem até o projeto.

Dá tiro às vezes. Acerta em mim, não quero. [...] Fica perigoso. [...] Eu vou pra baixo da cama às vezes. (Bernardo, 10 anos, aluno)

Às vezes dá tiro de manhã. Daí tipo eu não venho. [...] Minha mãe fica preocupada. (Helen, 11 anos, aluno)

As famílias têm medo que eles saiam de casa, porque pode ser nove horas da manhã, dez horas, quatro horas, três horas, dá tiroteio aqui dentro. [...] Então [...] preferem que os filhos fiquem em casa com porta fechada e não vão. (Amanda, profissional FAS)

Problemas gerados por rixas entre gangues, violência e medo são também barreiras para a participação em outros projetos sociais (GONÇALVES, 2003; MELO, 2005; VIANNA; LOVISOLO, 2009). Além das ruas, as famílias e a vizinhança de crianças e adolescentes pobres são também percebidos como "negativos" (THOMASSIM, 2010). Elas são muitas vezes avaliadas como "patológicas", "desorganizadas", e prejudiciais para a formação das mesmas (FONSECA, 2006). Para vários profissionais que entrevistamos, o projeto significa proteção contra a dura realidade que os alunos vivem em suas casas.

$\mathrm{Eu}$ acredito que pra algumas delas [crianças] deve ser muito difícil de conviver com a família [...] Deve ser desagradável ficar em casa. Alguns apanham, alguns moram sozinhos, moram em becos e ninguém cuida muito deles. E aqui eles têm esse aconchego [...] Imagine você ficar em casa com aquele climão assim. Aqui é um refúgio. (Bianca, profissional IC) 
[A casa deles] além de ser desagradável, encontra com aquela situação, aquela realidade triste. [...] Eu acho que perto da realidade deles aqui é o paraíso, né? (Laura, profissional FAS)

De acordo com todos os profissionais entrevistados, a maior parte dos alunos está constantemente exposta à violência, criminalidade, tráfico e consumo de drogas. A seguinte passagem, entre muitas outras, reflete esta crença:

Eles vivem dentro de um contexto onde eles aprendem desde pequenininho aquelas situações. [...] Vou dar um exemplo. [...] Eu sou uma moradora da Vila e eu sou traficante. Aí meu filho também vai ser traficante, né? Porque é viável pro filho ser traficante e pra mim também. Se eu ganho dinheiro, ele vai aprender a ganhar dinheiro, o filho dele também vai aprender a ganhar dinheiro com isso. [...] Vai de geração em geração. (Débora, profissional FAS)

Segundo os profissionais da FAS, o projeto também significa proteção contra situações de trabalho infantil.

A Vila é composta na maioria por coletadores de papel, né? Praticamente se eles não estão no contraturno, ou eles ficam sozinhos ou vão junto com os pais coletar. Então nosso trabalho é nesse sentido, de tirar a criança do trabalho infantil, entende? (Rosângela, profissional FAS)

Embora o envolvimento de crianças e adolescentes neste tipo de trabalho seja avaliado como negativo pelos profissionais que entrevistamos, talvez para os pais, levar seus filhos para o trabalho signifique protegê-los das ruas e/ou de prepará-los para o futuro.

\subsection{O PROJETO COMO UM ESPAÇO DE APRENDIZAGEM}

Enquanto as ruas e, em alguns casos, as famílias da Vila são tomados como negativos para o processo de formação de crianças e adolescentes, o projeto é percebido por profissionais e por alunos 
e seus familiares como um espaço capaz de promover "socialização positiva" e diferentes tipos de aprendizagem.

Se eles não viessem pra cá eles iriam ficar intoxicados com aquela cultura. [...]. Como eles estão aqui e a gente tem muita oportunidade de levar eles pra lugares e mostrar pra eles opções até de futuro, de profissão. (Bianca, profissional IC)

A gente aprende um monte de coisa legal. [...] Ensinam educação pra gente, esporte, pintar, a escrever. (Helen, 11 anos, aluno)

$\mathrm{Eu}$ gosto que eles aprendem mais as coisas, né? Aprendem a ser mais, a [pausa], a ter educação com as pessoas assim. Aprendem coisas novas, né? (Margarete, mãe)

Embora o projeto não tenha o objetivo de promover reforço escolar, e embora nenhum dos profissionais entrevistados tenha alegado que vise promover o desenvolvimento acadêmico dos alunos, todas as mães e alguns dos alunos entrevistados percebem o EAVT como um espaço que auxilia no desempenho de tarefas escolares. Esta crença pode ser observada, por exemplo, nas seguintes passagens:

Tem complemento do colégio, né? [...] Estar auxiliando ele no colégio porque quando tem dificuldade e passa pra alguém que saiba um pouquinho mais eles estão ajudando. (Eva, mãe)

Se a gente trazer as tarefas que eles passam na escola, eles ensinam a gente a fazer aqui, né? Porque em casa às vezes não tem ninguém que ensinar, mas aqui tem. (Nicole, 11 anos, participante)

O desenvolvimento de valores, principalmente o "respeito ao próximo", também foi apontado por parte das crianças e adolescentes como um dos benefícios do projeto.

Eles dão educação, por isso que eu gosto desse projeto. [...] Educação pra nós. [...] Eles passam pra não brigar, pra não, pra não xingar. (Eduardo, 9 anos, participante)

Movimento, Porto Alegre, v. 17, n. 04, p. 145-163, out/dez de 2011. 
Eles fala pra respeitar os outros. [...] Eles educam a gente, a gente respeita eles, os mais velhos. (Gisele, 11 anos, participante)

Todas as mães e profissionais que entrevistamos alegaram que as crianças e adolescentes melhoraram seu comportamento em diferentes sentidos, conforme se pode observar, por exemplo, nas seguintes passagens:

É legal ver assim o desenvolvimento deles e a mudança de comportamento. [...] Você vê [...] o jeito que eles chegaram [...] completamente diferente do que eles estão agora. Bem mais educados. (Cristiana, profissional IC)

Melhoraram bastante. [...] Bem mais rebeldes é o que eles eram. [...] Não queriam participar de nada dentro de casa, era só na rua. [...] Daí depois começou a mudar. [...] Esse fim de ano então, [...] nem tem reclamação no colégio, também estão super bem. (Valéria, mãe)

Para os profissionais entrevistados, a participação no EA-VT está relacionada com a promoção de "novas" e "diferentes" perspectivas de vida.

O objetivo maior [...] é resgatar na verdade as crianças do meio que eles vivem, porque ali a Vila é bem barra pesada mesmo. [...] E tentar fazer com que eles percebam que existe um mundo fora do mundo deles, né? E que existe uma sociedade que tipo melhor, vamos dizer assim, que a que eles vivem, né? (Cristiana, profissional IC)

Mostrar pra ela que não existe só de repente aquela realidade onde ela vive, né? De drogas, de brigas, de vícios e matança, né? Que tem muito na Vila. Mas que existe um outro mundo. [...] Mudar a vida e os pensamentos das crianças pra uma coisa boa [...]. Tirar essas crianças das ruas e dar uma nova condição de vida pra elas. (Clarissa, profissional FAS)

Para todas as crianças e adolescentes que entrevistamos, assim como para participantes de outros projetos sociais esportivos 
(ZALUAR, 1994; MELLO; FERREIRA NETO; VOTRE, 2009), a iniciação e/ou aperfeiçoamento esportivo é um dos principais tipos de aprendizagem promovido por estes projetos. Os profissionais do IC acreditam que o esporte é uma ferramenta que promove a incorporação de valores e de bons comportamentos. Esta crença é comum também no caso de trabalhadores envolvidos com outros projetos sociais (ZALUAR, 1994; GONÇALVES, 2003; GUEDES et al., 2006; SILVEIRA, 2006; VARGAS, 2007). Tanto em nosso estudo como em outros, os objetivos e as justificativas do uso do esporte estão baseados na crença de que existem qualidades positivas intrínsecas ao mesmo (THOMASSIM, 2010). Ou seja, o esporte é percebido como um meio de formação (MELO, 2005).

Embora muitos considerem o esporte como intrinsecamente positivo, ele deve ser entendido no contexto das relações sociais (BARBIRATO, 2005). São as relações sociais em um determinado contexto que dão significados ao mesmo, e não o inverso (THOMASSIM; STIGGER, 2009). Isto não significa dizer que o esporte não deva e não possa ser entendido como uma ferramenta educativa. Significa dizer que embora ele tenha alguns elementos que o caracterizam como tal, "esta atividade é praticada por indivíduos que dão a cada um destes elementos um peso na constituição da sua prática esportiva particular" (STIGGER, 2002, p. 250). Apesar da crença dos profissionais do IC acerca das qualidades intrinsicamente positivas do esporte, observamos que os mesmos precisavam frequentemente intervir, mediar conflitos, e reprimir e premiar comportamentos no sentido de minimizar problemas tais como agressividade e violência que se manifestavam durante a prática esportiva. Neste sentido, é possível concluir que a prática esportiva pode também ensinar comportamentos "negativos" e contrários aos discursos e objetivos comumente encontrados em projetos sociais (LAZZARI, 2009).

Enquanto que para os profissionais a preocupação com o futuro de alunos do EA-VT está relacionada com visualização de "novas" e "diferentes" perspectivas de vida através das aprendizagens proporcionadas pelo projeto, para as mães a preocupação com o 
futuro de seus filhos está ligada a perspectivas de cursos profissionalizantes e emprego. Ou seja, segundo a grande maioria das mães entrevistadas, a participação de seus filhos no EA-VT funciona como uma espécie de investimento.

Tem curso, né? [...] Tudo através deles. Eu acho melhor isso aí. Porque se eles não tivessem aqui no projeto não ia ter chance de participar de alguma coisa, né? (Vilma, mãe)

Daí ela [filha] vai fazer algum cursinho, o que eles encaminharem. Eu vou exigir que ela faça, que se eles derem um curso, alguma coisa, vai ser muito bom. (Margarete, mãe)

A preocupação com encaminhamento profissional através de projetos sociais é comum. No caso de várias realidades, no entanto, tal preocupação está relacionada com uma expectativa de ascensão social através do esporte (ZALUAR, 1994; BARBIRATO, 2005; VARGAS, 2007; MARQUES; KRUG, 2008). No caso de nosso estudo, verificamos que esta preocupação está mais relacionada com o encaminhamento para cursos profissionalizantes e programas de primeiro emprego (BARBIRATO, 2005; THOMASSIM, 2010).

\subsection{O PROJETO COMO UM ESPAÇO PARA BRINCAR, JOGAR E SE DIVERTIR}

Ao mesmo tempo em que para profissionais e mães de alunos, o EA-VT tem o sentido de proteção de "males" e promoção de diferentes tipos de aprendizagem, para crianças e adolescentes o seu envolvimento no EA-VT está diretamente vinculado ao seu interesse pelas atividades ofertadas. Grande parte dos alunos que entrevistamos disseram que escolheram o EA-VT porque o mesmo era o projeto mais atrativo da Vila Torres.

Porque eu acho esse o mais bom. [...] Porque os outros é só pintar só, e não tem aula assim como nós, que não tem vôlei, não tem futebol, é só pintar só. (Rebeca, 11 anos, aluno)

Esse daqui é mais melhor. [...] Ah, tem bastante brincadeira, tem passeio. Tem mais passeio que nos outros projetos. (Fábio, 10 anos, aluno) 
Ao comentarem sobre o que acham do projeto, todos os alunos afirmaram que gostam do mesmo, principalmente porque lá podem praticar esportes e participar em brincadeiras e passeios para locais tais como centros desportivos, piscinas, cinema e parques.

Legal. [...] Ah porque tem brincadeira, nós faz esporte. E tem bastante passeio. (Paola, 12 anos, alunos)

Legal. [...] Porque tem brincadeira, tem jogos, tem campeonatos. (Murilo, 13 anos, aluno)

Para vários entrevistados, participar do projeto é melhor do que ficar em casa "fazendo nada" ou fazendo coisas que não gostam.

Porque em casa você fica sem fazer nada, fora os serviços de casa, né? Daí é chato. (Nicole, 11 anos, aluno)

Porque daí eu brinco, eu não fico sozinha. [...] Pra mim brincar com elas, se não eu vou ficar sozinha. (Rebeca, 11 anos, aluno)

O gosto por atividades esportivas foi constatado em várias pesquisas sobre outros projetos. Exemplos disto são os estudos sobre o Programa Privado de Iniciação Esportiva (PRIESP) e do Projeto do Irmão Menor (PIM), realizado por Zaluar (1994); Projeto Vila Olímpica da Estação Primeira de Mangueira (GONÇALVES, 2003); Projeto Esporte Clube Cidadão (VARGAS, 2007); Programa Segundo Tempo (MARQUES; KRUG, 2008); e Programa Comunidade Escola (SOUZA et al., 2010).

As amizades e a companhia das demais crianças e adolescentes também foram destacadas como importantes fatores para a participação no EA-VT.

Gosto. [...] É por causa que aqui eu tenho mais amigas, né? (Giovana, 12 anos, aluno)

A amizade conta. Eles estão pela amizade e se eles não tivessem aqui eles estariam em casa fazendo o que? [...] Aqui eles vão estar com amigo. (Eva, mãe) 
Às vezes eles vêm pra cá por causa das amizades. É a companhia pra vim e pra voltar. (Liliane, profissional FAS)

As amizades e o convívio com demais participantes também aparecem em outros estudos como importantes fatores para o envolvimento em projetos sociais (ZALUAR, 1994; MOLINA, 2007; VARGAS, 2007; MARQUES; KRUG, 2008; SOUZA et al., 2010; THOMASSIM, 2010). Ou seja, para muitas crianças e adolescentes, participar em projetos sociais significa estar com seus pares.

\section{Considerações Finals}

O projeto Esporte em Ação - Núcleo Vila Torres (EA-VT) é percebido por todos os profissionais, mães e alguns participantes que entrevistamos como um espaço que protege crianças e adolescentes de "coisas que não prestam", "más influências" e da violência das ruas. O EA-VT é também percebido como um espaço que propicia diferentes tipos de aprendizagem, como por exemplo, apoio escolar, iniciação e/ou aperfeiçoamento esportivo, desenvolvimento de valores, melhoria de comportamento e preparação para o futuro. Para as crianças e adolescentes, o mesmo significa principalmente diversão, brincadeiras, oportunidades para estarem com seus pares e para se envolverem com atividades que consideram prazerosas, tais como práticas desportivas e passeios.

Ao analisarmos os diferentes significados positivos atribuídos a projetos sociais tais como o EA-VT, não podemos deixar de considerar as complexidades envolvidas no processo de socialização de crianças e adolescentes. Estes projetos são apenas um dentre vários espaços socializadores onde os mesmos se inserem. Portanto, a incorporação de valores e comportamentos positivos nem sempre se dá da forma esperada. Também não podemos deixar de ponderar que, embora projetos sociais como o EA-VT sejam entendidos como espaços seguros quando comparados às ruas, a participação nos mesmos, para muitos, depende de uma avaliação de riscos, principalmente na questão do trajeto até o local das atividades. Existe, 
portanto, uma demanda de políticas públicas no sentido de se garantir a segurança pública para que as crianças e adolescentes possam frequientar o projeto. Conforme discutimos anteriormente, o projeto EA-VT tem significados importantes na vida de seus alunos e pais de alunos. Diante da realidade em que vivemos, este projeto, entre outros, se fazem necessários. Acreditamos, no entanto, que o ideal seria que todas as crianças e adolescentes tivessem acesso a programas de educação integral ${ }^{8}$ em tempo integral de boa qualidade, dentro da própria escola. Na medida em que isto se tornar realidade, projetos sociais, tais como o estudado, não mais serão necessários.

${ }^{8}$ Educação integral significa educação do ser humano como um todo, em seus aspectos cognitivos, físicos, emocionais e sociais. 
Meanings of a sport social project: a study from the perspective of professionals, parents, children and adolescents

Abstract: This study aimed at exploring the main meanings assigned to the project "Esporte em Ação Unit Vila Torres, Curitiba/PR, according to the perception of students, parents, and professionals involved with the project. The research was qualitative and exploratory, and the data were collected through semistructured and open interviews with professionals, parents, and students. The analysis was based on grounded theory procedures. The project is perceived as a space that protects the participants against "evils of the streets", as a learning space, and as a space to play, have fun and be with friends.

Keywords: Social project. Participation. Children. Adolescentes.

\section{Significados de un proyecto social de deporte: un estudio desde la perspectiva de profesionales, padres, niños y adolescentes. \\ Resumen: Este estudio tuvo como objetivo explorar los principales significados asignados al proyecto "Esporte em Ação" - Vila Torres, en Curitiba / PR, de acuerdo con la percepción de los estudiantes, padres y profesionales involucrados en el proyecto. La investigación fue de corte cualitativo y exploratorio, y los datos fueron recogidos a través de entrevistas semi-estructuradas y abiertas con los profesionales, padres y estudiantes. El análisis se basó en procedimientos de la teoría fundamentada. Se concluyó que el proyecto se percibe como un espacio que protege a los niños de los "males de las calles", como un espacio de aprendizaje, e como um espacio para jugar, divertirse y estar con amigos. \\ Palabras clave: Proyecto social. Niños. Adolescentes.}




\section{REFERÊNCIAS}

BARBIRATO, F. R. A socialização no contexto de projetos esportivos: um estudo de caso na Fundação Gol de Letra. 147 f. Dissertação (Mestrado em Educação) - Centro de Estudos Sociais Aplicados, Universidade Federal Fluminense, Niterói, 2005. Disponível em: <http://www.uff.br/pos_educacao/joomla/images/ stories/Teses/fernandab.pdf>. Acesso em: 23 jun. 2010.

BRETÃS, Angela. Onde mora o perigo? Discutindo uma suposta relação entre ociosidade, pobreza e criminalidade. Educação, esporte e lazer, 9 jun. 2007. Disponível em: <http://www.tvebrasil.com.br/salto/boletins2007/eel/ 070611_educacaoesporte.doc>. Acesso em: 23 abr. 2009.

FONSECA, C. Classe e recusa etnográfica. In: BRITES, J.; FONSECA, C. (Org.). Etnografias da participação. Santa Cruz: EDUNISC, 2006.

GLASER, B. G.; STRAUSS, A. L. The discovery of grounded theory: strategies for qualitative research. Chicago: Aldine, 1967.

GONÇALVES, M. A. R. A vila olímpica da Verde-e-Rosa. Rio de Janeiro: FGV, 2003.

GUEDES, S. L. et al. Projetos sociais esportivos: notas de pesquisa. In: ENCONTRO REGIONAL DE HISTÓRIA, XII, 2006, Niterói. Anais... Rio de Janeiro: ANPUH, 2006. p. 92-92. Disponível em: <http://www.rj.anpuh.org/Anais/2006/conferencias/ Simoni\%20LGuedes,\%20Julio\%20Davies,\%20Michelle\%20ARodrigues\%20e\% 20Rafael\%20MSantos.pdf>. Acesso em: 23 abr. 2009.

INSTITUTO COMPARTILHAR. [Site] Disponível em: <http://www.compartilhar. org.br>. Acesso em: 10 abr. 2009.

LAZZARI, A. A socialização de crianças e adolescentes no contexto de um projeto social de tênis. 55 f. Monografia (Graduação em Educação Física) - Universidade Federal do Rio Grande do Sul, Porto Alegre, 2009. Disponível em: <http://www.Iume.ufrgs.br/bitstream/handle/10183/18893/ 000732141.pdf?sequence=>. Acesso em: 13 nov. 2010.

MARQUES, M. N.; KRUG, H. N. As contribuições do Programa Segundo Tempo para os discentes de uma escola estadual de Santa Maria (RS): um estudo de caso fenomenológico. Revista Digital Ef Deportes, Buenos Aires, ano 13, no. 124, set. 2008. Disponível em: <http://www.efdeportes.com/efd124/as-contribuicoesdo-programa-segundo-tempo.htm>. Acesso em: 08 jun. 2009.

MELLO, A. da S.; FERREIRA NETO, A.; VOTRE, S. J. Intervenção da Educação Física em projetos sociais: uma experiência de cidadania e esporte em Vila Velha (ES). Revista Brasileira de Ciências do Esporte, Campinhas, v. 31, n. 1, p. 7591, set. 2009. Disponível em: <http://www.rbceonline.org.br/revista/ index. php? journal=RBCE\&page=article \&op=view \& path $\% 5 B \% 5 D=633 \&$ path $\%$ $5 \mathrm{~B} \% 5 \mathrm{D}=393>$. Acesso em: 02 out. 2009. 
MELO, M. P. de. Lazer, esporte e cidadania: debatendo a nova moda do momento. Movimento, Porto Alegre, v. 10, n. 2, p. 105-122, maio/ago. 2004. Disponível em: <http://www.seer.ufrgs.br/index.php/Movimento/article/viewFile/2836/1449>. Acesso em: 02 jul. 2009.

Esporte e juventude pobre: políticas públicas de lazer na Vila Olímpica da Maré. Campinas, SP: Autores Associados, 2005.

Esporte social futebol clube: contradições e dilemas em nosso tempo. Democracia Viva, n. 32, p. 54-58, jun 2007a. Especial Pan 2007. Disponível em: <http://www.ibase.br/userimages/dv35_pan5.pdf>. Acesso em: 23/04/2009.

O chamado terceiro setor entra em campo: políticas públicas de esporte no governo lula e o aprofundamento do projeto neoliberal da terceira via. Licere, Belo Horizonte, v. 10, p. 1-35, 2007b. Disponível em: <http://www.lazer.eefd.ufrj.br/ licere/pdf/licereV10N02_a6.pdf>. Acesso em: 23 abr. 2009.

MENDES, V. da R. et al. Como os pais percebem a participação dos filhos no Programa Segundo Tempo. In: CONGRESSO BRASILEIRO DE CIÊNCIAS DO ESPORTE, XV, 2007, Recife. Anais... Recife: CBCE, 2007. Disponível em: <http:// www.cbce.org.br/cd/resumos/265.pdf>. Acesso em: 23 abr. 2009.

MOLINA, R. K. Políticas de esporte e projetos sociais: impactos nos processos de subjetivação dos jovens. In: CONGRESSO BRASILEIRO DE CIÊNCIAS DO ESPORTE, XV, Recife, 2007. Anais... Recife: CBCE, 2007. Disponível em: <http:// www.cbce.org.br/cd/resumos/278.pdf>. Acesso em: 23 abr. 2009.

PATTON, M. Qualitative evaluation and research methods. 2. ed. Newbury Park: SAGE, 1990.

SOUZA, D. L. de et al. Determinantes para a implementação de um projeto social. Motriz, Rio Claro, v. 16, n. 3, p. 689-700, jul./set. 2010. Disponível em: <http:// www. periodicos.rc.biblioteca.unesp.br/index.php/motriz/article/view/19806574.2010v16n3p689/pdf_44>. Acesso em: 14 out. 2010.

SILVEIRA, J. Desenvolvimento humano, responsabilidade social e educação no capitalismo: investigando o programa "Educação Pelo Esporte" do Instituto Ayrton Senna. 151 f. Dissertação (Mestrado em Educação Física) - Centro de Desportos da Universidade Federal de Santa Catarina, Florianópolis, 2007. Disponível em: <http://tede.ufsc.br/teses/PGEF0153.pdf>. Acesso em: 23 abr. 2009.

STIGGER, M. P. Esporte, lazer e estilos de vida: um estudo etnográfico. Campinas: Autores Associados, 2002.

STRAUSS, A. L.; CORBIN, J. Introduction to qualitative research: grounded theory procedures and techniques. Beverly Hills: Sage, 1990.

THIN, D. Para uma análise das relações entre famílias populares e escola: confrontação entre lógicas socializadoras. Revista Brasileira de Educação, v. 11, n. 32, maio/ago. 2006, p. 211-225. Disponível em: <http://www.scielo.br/pdf/ rbedu/v11n32/a02v11n32.pdf>. Acesso em: $10 \mathrm{dez} .2010$. 
THOMASSIM, L. E. C. Uma alternativa metodológica para a análise dos projetos sociais esportivos. 2006. In: ENAREL, 18., 2006, Curitiba. Anais... Curitiba: PUCPR, 2006.

Conflitos em torno do lazer: o sentido das práticas de responsabilidade social na contramão dos direitos sociais. In: SILVA, M. R. da. (Org.) Esporte, educação, estado e sociedade. Chapecó: Argos, 2007. p. 257-281.

O "público-alvo" nos bastidores da política: um estudo sobre o cotidiano de crianças e adolescentes que participam de projetos sociais esportivos. 296 f. Tese (Doutorado em Ciências do Movimento Humano) - Programa de PósGraduação em Ciência do Movimento Humano, Universidade Federal do rio Grande do Sul, 2010.

THOMASSIM, L. E. C.; STIGGER, M. P. Super-oferta de projetos sociais esportivos: superando as imagens públicas idealizadas sobre essas ações. In: SEMINÁRIO NACIONAL POLÍTICA \& SOCILOGIA UFPR 1. 2009, Curitiba. Anais... Curitiba: UFPR, 2009. CD-Rom

VARGAS, L. S. Esporte, interação e inclusão social: um estudo etnográfico do "Projeto Esporte Clube Cidadão". 119 f. Dissertação (Mestrado em Ciências Sociais) - Departamento de Ciências Sociais Aplicadas, Universidade do Vale do Rio dos Sinos, São Leopoldo, 2007. Disponível em: <http://bdtd.unisinos.br/tde_busca/ arquivo.php?codArquivo=434>. Acesso em: 26 abr. 2009.

VIANNA, J. A.; LOVISOLO, H. R. Projetos de inclusão social através do esporte: notas sobre a avaliação. Movimento, Porto Alegre, v. 15, n. 3, p. 145-162, jul./set. 2009. Disponível em: <http://www.seer.ufrgs.br/index.php/Movimento/article/view/ 5190/5583>. Acesso em: 23 set. 2009.

VILA NOVA, S. Introdução a Sociologia. São Paulo: Atlas, 1981.

ZALUAR, A. Cidadãos não vão ao paraíso. São Paulo: Escuta, 1994.

Endereço para correspondência:

Doralice Lange de Souza

Av. Senador Salgado Filho, 1800 - casa II

Cep. 81510-001

Guabirotuba - Curitiba/PR

Recebido em: 09.08.2011

Aprovado em: 13.12.2011

ovimento, Porto Alegre, v. 17, n. 04, p. 145-163, out/dez de 2011. 
